Article

\title{
A Novel Sensor for Monitoring of Iron(III) Ions Based on Porphyrins
}

\section{Dana Vlascici ${ }^{1}$, Eugenia Fagadar-Cosma ${ }^{2, *}$, Iuliana Popa ${ }^{3}$, Vlad Chiriac ${ }^{1}$ and Mayte Gil-Agusti ${ }^{4}$}

1 Faculty of Chemistry-Biology-Geography, West University of Timisoara, Pestalozzi Street 16, 300115-Timisoara, Romania; E-Mail: danavlascici@yahoo.com

2 Institute of Chemistry Timisoara of Romanian Academy, M. Viteazul Ave. 24, 300223-Timisoara, Romania

3 National Institute of Research for Electrochemistry and Condensed Matter, Timisoara, Aurel Paunescu Podeanu Street 144, 300860-Timisoara, Romania; E-Mail: iuliana_p19@yahoo.com

4 Instituto Tecnológico de la Energía (ITE), Avenida Juan de la Cierva 24, 46980 Paterna, Valencia, Spain; E-Mail: mayte.gil@ite.es

* Author to whom correspondence should be addressed; E-Mail: efagadar@yahoo.com; Tel.: +40-256-491-818; Fax: +40-256-491-824.

Received: 9 April 2012; in revised form: 27 May 2012 / Accepted: 8 June 2012 /

Published: 13 June 2012

\begin{abstract}
Three $\mathrm{A}_{3} \mathrm{~B}$ porphyrins with mixed carboxy-, phenoxy-, pyridyl- and dimethoxysubstituent functionalization on the meso-phenyl groups were obtained by multicomponent synthesis, fully characterized and used as ionophores for preparing PVC-based membrane sensors selective to iron(III). The membranes have an ionophore:PVC:plasticizer composition ratio of 1:33:66. Sodium tetraphenylborate was used as additive $(20 \mathrm{~mol} \%$ relative to ionophore). The performance characteristics (linear concentration range, slope and selectivity) of the sensors were investigated. The best results were obtained for the membrane based on 5-(4-carboxyphenyl)-10,15,20-tris(4-phenoxyphenyl)-porphyrin plasticized with bis(2-ethylhexyl)sebacate, in a linear range from $1 \times 10^{-7}-1 \times 10^{-1} \mathrm{M}$ with a slope of $21.6 \mathrm{mV} /$ decade. The electrode showed high selectivity with respect to alkaline and heavy metal ions and a response time of $20 \mathrm{~s}$. The influence of $\mathrm{pH}$ on the sensor response was studied. The sensor was used for a period of six weeks and the utility has been tested for the quantitative determination of $\mathrm{Fe}$ (III) in recovered solutions from spent lithium ion batteries and for the quantitative determination of $\mathrm{Fe}$ (III) in tap water samples.
\end{abstract}


Keywords: porphyrins; ion-selective electrode; potentiometry; lithium ion batteries; iron(III); PVC membrane

\section{Introduction}

Iron is an essential element in biological processes, playing an important role as oxygen carrier, in storage and electron transport. This is the reason why major impacts can appear due to its metabolism deregulation. Thus, an abnormal higher level of iron in the body leads to haemochromatosis and its deficiency leads to anemia. Besides, technical developments regarding $\mathrm{Ni}$, Co and $\mathrm{Mn}$ recovery in the recycling process of Li-batteries implies iron monitoring in synthetic leach liquor resulted from reductive leaching. This is the reason why iron must be precisely determined in biological, chemical, environmental [1-12] and industrial samples [13,14].

In order to monitor $\mathrm{Fe}^{3+}$ ions from different samples, many techniques have been used. A sequential injection procedure was used for determination of $\mathrm{Fe}$ (II) and $\mathrm{Fe}$ (III) in aquatic samples by a complex procedure. Fe(II) was determined by complexation with 1,10-phenantroline and Fe(III) analysis was performed after reduction in Jones and copperized cadmium columns. For Fe(III) the quantification limits were 0.05 and $0.1 \mathrm{mg} \mathrm{L}^{-1}$, with a sampling frequency of $20 \mathrm{~h}^{-1}$ [1]. Rapid and low cost colorimetric spot-test determination of $\mathrm{Fe}$ (III) was applicable for concentration of Fe(III) from 6 to $45 \mathrm{mmol} \cdot \mathrm{L}^{-1}$ [2]. Separation and preconcentration of $\mathrm{Fe}(\mathrm{III})$ ions in various water samples was achieved by sorption at a $\mathrm{pH}$ of 3.5 in a minicolumn obtained from Amberlite XAD-4, functionalized with 2,3-dihydroxybenzoic acid by coupling it through an $-\mathrm{N}=\mathrm{N}-$ spacer, then eluted using $\mathrm{H}_{3} \mathrm{PO}_{4}$. The released amount of $\mathrm{Fe}^{3+}$ was determined by flame atomic absorption spectrometry with a recovery of more than $98 \%$ [3]. Inductively coupled plasma atomic emission spectrometry was used for determination of $\mathrm{Fe}$ (III) in aqueous solutions by modified nanometer device based on $\mathrm{SiO}_{2}$ using 5-sulfosalicylic acid as a solid-phase extractant for separation and preconcentration [4].

The use of ion-selective electrodes for iron(III) detection as a fast and low-cost method was also reported in the last years. A sensor based on 2-[(2-hydroxy-1-propenylbuta-1,3-dienylimino)-methyl]4-p-tolylazophenol as carrier for the determination of $\mathrm{Fe}(\mathrm{III})$ in the presence of $\mathrm{Fe}(\mathrm{II})$, in a concentration range of $3.5 \times 10^{-6}-4 \times 10^{-2} \mathrm{M}$, with a super Nernstian slope of $28.5( \pm 0.5) \mathrm{mV} / \mathrm{decade}$ and in a pH range from 4.5 to 6.5 has been reported [5]. Mollagh et al. [6] have developed PVC membrane and coated wire sensors based on 1-phenyl-3-pyridin-2-ylthiourea with the best performances in the range $3.0 \times 10^{-7}-1.0 \times 10^{-2} \mathrm{M}$ and a slope of $20.2 \pm 0.8 \mathrm{mV} / \mathrm{decade}$. An iron(III) ion-selective sensor based on a $\mu$-bis(tridentate) ligand was developed by Gupta and collaborators [7]. The sensor showed a linear potential response in a concentration range $6.3 \times 10^{-6}-1.0 \times 10^{-1} \mathrm{M}$ with a Nernstian slope of $20.0 \mathrm{mV} /$ decade, between $\mathrm{pH} 3.5$ and 5.5. Iron was determined in biological and non-biological samples using a sensor based on 1,1'-(iminobis(methan-1-yl-1-ylidene))dinaphtalen-2-ol as carrier with a concentration range between $1.0 \times 10^{-7}-1.0 \times 10^{-1} \mathrm{M}$ and a slope of $19.9 \mathrm{mV} /$ decade [8]. S-Methyl $N$-(methylcarbamoyloxy)thioacetimidate was used as ionophore [9] in another Fe(III)-selective sensor which works in the range $9.1 \times 10^{-6}-1.0 \times 10^{-1} \mathrm{M}$ with a slope of $21.2 \mathrm{mV} / \mathrm{decade}$. An iron ion sensor based on functionalized $\mathrm{ZnO}$ nanorods has been developed [10], which was observed to be 
linear in the concentration range from $10^{-5}$ to $10^{-2} \mathrm{M}$ with sensitivity of $70.2 \pm 2.81 \mathrm{mV} /$ decade. Using bis-benzilthiocarbohydrazide as sensing material, the autors [11] have reported the fabrication of an iron(III)-selective sensor which works from $1.0 \times 10^{-7}$ to $1.0 \times 10^{-2} \mathrm{M}$ with a Nernstian slope in a $\mathrm{pH}$ range of 1.6-4.3.

Only one potentiometric sensor for $\mathrm{Fe}^{3+}$ ions detection based on porphyrins, namely: 5,10,15,20-tetrakis(pentaflurophenyl)-21H,23H-porphyrin, as membrane carrier was presented [12]. The porphyrin-based sensor revealed good selectivity for $\mathrm{Fe}^{3+}$ over a wide variety of other cations at pH 3-4 in the concentration range $1.0 \times 10^{-4}-1.0 \times 10^{-6} \mathrm{M}$. This method was applied to the direct determination of iron in tap water samples.

In the present paper we have used three $\mathrm{A}_{3} \mathrm{~B}$ porphyrins with mixed functionalization to obtain iron(III)-potentiometric sensors. The best results were obtained for the sensor based on a novel synthesized porphyrin structure, 5-(4-carboxyphenyl)-10,15,20-tris(4-phenoxyphenyl)-porphyrin (Figure 1) plasticized with bis(2-ethylhexyl) sebacate. The sensor was used for iron monitoring in synthetic leach liquor resulting from reductive leaching [13] in the recycling process of Li-batteries. The leaching solution from spent battery material contains large quantities of valuable metals $\mathrm{Ni}$, $\mathrm{Co}$ and $\mathrm{Mn}$, as well as impurities, $\mathrm{Cu}$ and $\mathrm{Fe}$. Recent developments regarding $\mathrm{Ni}$, $\mathrm{Co}$ and $\mathrm{Mn}$ recovery implies that copper is removed through replacement by iron powder, followed by iron precipitation. The final results show that $\mathrm{Cu}$ and Fe can be removed $99 \mathrm{wt}$ \% at the least [14]. For the monitoring of iron removal from leach solution, it was formulated the present new sensor based on porphyrin ionophore.

Figure 1. The chemical structure of 5-(4-carboxyphenyl)- 10,15,20-tris(4-phenoxyphenyl)-porphyrin.

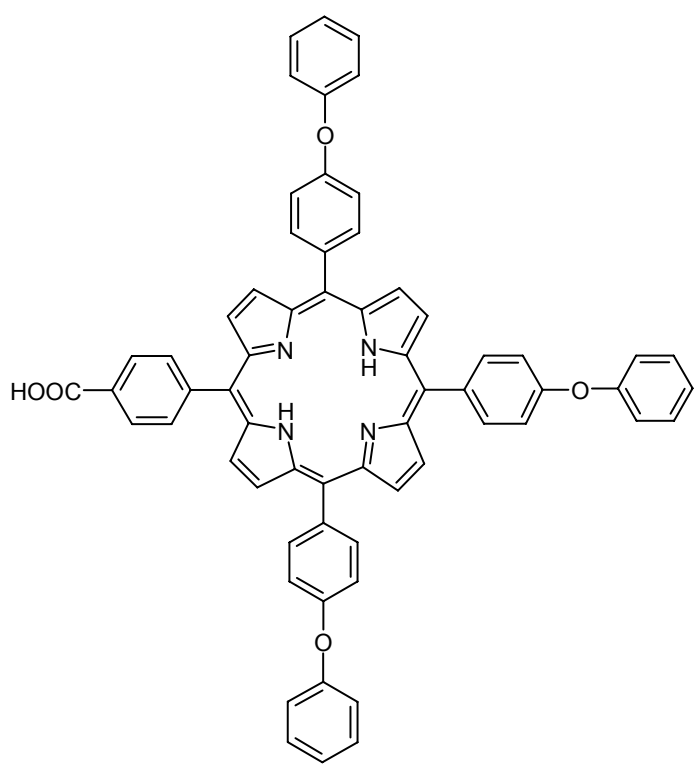

\section{Experimental}

\subsection{Reagents}

The porphyrin 5-(4-carboxyphenyl)-10,15,20-tris(4-phenoxyphenyl)-porphyrin (P1) was synthesized as presented below. The porphyrins 5-(4-pyridyl)-10,15,20-tris(3,4-dimethoxyphenyl)-porphyrin (P2) 
and 5-(4-pyridyl)-10,15,20-tris(4-phenoxyphenyl)-porphyrin (P3) were synthesized, purified and characterized in accordance with previously published procedures [15].

For membrane preparation, poly(vinyl)chloride (PVC) high molecular weight, bis(2-ethylhexyl)sebacate (DOS), o-nitrophenyloctylether (NPOE), dioctylphtalate (DOP), sodium tetraphenylborate (NaTPB) and tetrahydrofuran (THF) were purchased from Fluka and Merck. All salts, acids and base were of analytical reagent grade. Double distilled water was used. The performance of each sensor was investigated by measuring its potential in the concentration range $10^{-5}-10^{-1} \mathrm{M}$ of different cationic solutions. In the case of iron(III) the solutions were made in a concentration range up to $10^{-7} \mathrm{M}$. Stock solutions, $0.1 \mathrm{M}$, were prepared by dissolving metal chlorides in double distilled water and standardized if necessary. All working solutions were prepared by gradual dilution of the stock solutions.

\subsection{Apparatus}

FT-IR spectra were recorded on a JASCO $430 \mathrm{FT}-\mathrm{IR}$, as $\mathrm{KBr}$ pellets, in the $4,000-400 \mathrm{~cm}^{-1}$ range. UV-visible spectra were recorded on a Perkin Elmer LAMBDA 12 UV/VIS spectrometer and on a JASCO UV-visible spectrometer, model V-650. Absorption spectra were recorded at ambient temperature using $1 \mathrm{~cm}$ path length cells. ${ }^{1} \mathrm{H}-\mathrm{NMR}$ spectra were obtained on Bruker Avance DRX 400 equipment, using $\mathrm{CDCl}_{3}$ as solvent. The HPLC analysis were performed on a JASCO apparatus equipped with a silica gel KROMASIL 100 SIL $5 \mu \mathrm{m} 250 \times 4.0 \mathrm{~mm}$ column and a MD 1510 detector, at ambient temperature, using UV detection at $419 \mathrm{~nm}$. For MS analysis of porphyrin base an Electrospray Ionization Bruker Esquire 6000 mass spectrometer was used. Thin-layer chromatography (TLC) was performed on silica gel plate $60 \mathrm{~F}_{254}$ pre-coated aluminum sheets from Merck.

\subsection{Ionophore Synthesis and Characterization}

The most used direct route to obtain a carboxylic acid porphyrin derivative is through hydrolysis of ester-type porphyrin derivatives, usually ester type Zn-metalloporphyrins [16]. In the reported study, the synthesis of unsymmetrical mixed substituted 5-(4-carboxyphenyl)-10,15,20-tris(4-phenoxyphenyl)-porphyrin was based on modified previous literature data [17,18] condensing a mixture of pyrrole and two appropriately substituted benzaldehydes in a particular ratio, as follows: to a solution consisting of 4-carboxymethylbenzaldehyde (1.58 g, $9.69 \mathrm{mmol})$ and 4-phenoxybenzaldehyde (5 $\mathrm{mL}$, $29.08 \mathrm{mmol})$ dissolved in propionic acid $(284 \mathrm{~mL})$ as solvent, propionic anhydride $(4.97 \mathrm{~mL}, 38.77 \mathrm{mmol})$ was added. The mixture was brought to reflux under vigorous stirring. For $25 \mathrm{~min}$ a solution of pyrrole (2.689 $\mathrm{mL}, 38.77 \mathrm{mmol})$ in propionic acid $(6.45 \mathrm{~mL})$ was continuously added to this mixture. The reflux is maintained for $3.5 \mathrm{~h}$. The products were cooled to room temperature and a violet precipitate is formed. The solid is several times washed with hot water, and then solved again in THF over anhydrous $\mathrm{Na}_{2} \mathrm{SO}_{4}$ to remove the humidity. To the new filtered solution, $100 \mathrm{~mL}$ hexane were added and filtered next day. The methyl ester was hydrolyzed in basic condition using $\mathrm{KOH}$ in a mixture $\mathrm{MeOH} /$ water, followed by neutralization with dilute $\mathrm{HCl}$ [19]. The solid was separated on reversed phase analytical column chromatography $250 \times 4.0 \mathrm{~mm}$, KROMASIL 100, Sil, $5 \mu \mathrm{m}$ in a mixture of solvents: ethyl acetate-DMSO-propionic acid $=90: 10: 300 \mu \mathrm{L}$. The retention time for the 5-(4-carboxyphenyl)-10,15,20-tris(4-phenoxyphenyl)-porphyrin was $2.69 \mathrm{~min}$, being the major peak, eluted second. TLC analysis on a silica gel plate $60 \mathrm{~F}_{254}$ gave $\mathrm{R}_{\mathrm{f}}=0.38$ (EtOAc-hexane, 1:3, v/v). 
5-(4-carboxyphenyl)-10,15,20-tris(4-phenoxyphenyl)-porphyrin (P1): dark violet crystals; yield: 7.3\%; mp over $300{ }^{\circ} \mathrm{C}$; FT-IR $\left(v, \mathrm{~cm}^{-1}\right): 746$ and $796\left(\gamma \mathrm{C}-\mathrm{H}_{\text {pyrrole }}\right), 861,964,1,234$ (aromatic $\left.\mathrm{C}-\mathrm{O}-\mathrm{C}\right), 1,483$ $(\mathrm{C}-\mathrm{O}-\mathrm{C}$ and/or $v \mathrm{C}=\mathrm{N}), 1,587\left(v \mathrm{C}=\mathrm{C}_{\mathrm{Ph}}\right), 1,686(v \mathrm{C}=\mathrm{O}), 3,032.5\left(v \mathrm{C}-\mathrm{H}_{\mathrm{Ph}}\right), 3,311(v \mathrm{~N}-\mathrm{H}) ;{ }^{1} \mathrm{H}-\mathrm{NMR}$ $\left(\mathrm{CDCl}_{3}\right), \delta$, ppm: $8.92-8.94$ (d, 6H, $\beta$-pyrrole) 8.84 (bs, 2H, $\beta$-pyrrole), 8.53 (d, 4H, H-2,6 phenyl) 8.17-8.19 (d, 4H, H-2,6 phenyl), 7.50-7.59 (m, 8H, H-3,5 phenyl), 7.35-7.41 (m, 15H, H-phenyl), 2.70 (br s, 2H, internal-NH-pyrrole); UV-vis, THF ( $\lambda \max (\log \varepsilon): 418.48$ (5.22); 515.17 (4.53); 550.50 (4.32); 592.56 (4.11); 650.69 (4.04); HPLC $\mathrm{R}_{\mathrm{T}}$, min: 2.69; TLC (silica gel $60 \AA$, indicator $\mathrm{F}_{254}$, EtOAc-hexane, 1:3, v/v), $\mathrm{R}_{\mathrm{f}}: 0.38$; $\left.\mathrm{MS}\left(\mathrm{ESI}^{+}\right): m / z=935.2 \mathrm{M}\right]^{+}\left(\mathrm{C}_{63} \mathrm{H}_{42} \mathrm{~N}_{4} \mathrm{O}_{5}\right]^{+} \cdot$ molecular ion, calcd. for $\mathrm{M}]^{+} 935.03 \mathrm{~g} / \mathrm{mol}$; in the ${ }^{1} \mathrm{H}-\mathrm{NMR}$ spectrum of the methylic ester, a singlet signal located at $4.06 \mathrm{ppm}$, corresponding to the three protons of $-\mathrm{OCH}_{3}$ group is present.

\subsection{Electrode Membrane Preparation and Measurements}

The membranes have an ionophore-PVC-plasticizer in the ratio 1:33:66 composition. Sodium tetraphenylborate was used as additive (20 mol \% relative to ionophore). The electroactive material and the solvent mediator were mixed together, and then the PVC and the appropriate amount of THF were added and mixed to obtain a transparent solution. This solution was transferred onto a glass plate of $20 \mathrm{~cm}^{2}$, and the THF was allowed to evaporate at room temperature leaving a tough, flexible membrane embedded in a PVC matrix. An $8 \mathrm{~mm}$ diameter piece of membrane was cut out and assembled on the Fluka electrode body. The measurements were carried out at room temperature using a Hanna Instruments HI223 pH/mV-meter by setting up the following cell:

$\mathrm{Ag}|\mathrm{AgCl}| \mathrm{KCl}$ (sat)|sample|ion-selective membrane $\left|1.0 \times 10^{-2} \mathrm{M} \mathrm{Fe}^{3+}\right| \mathrm{AgCl}, \mathrm{Ag}$

Prior to EMF measurements, all the sensors were conditioned for $24 \mathrm{~h}$ by soaking in $0.01 \mathrm{M} \mathrm{FeCl}_{3}$. Potentiometric selectivity coefficients were determined according to the separate solution method by using the experimental EMF values obtained for $0.01 \mathrm{M}$ of the tested cations and a theoretical slope of $19.7 \mathrm{mV} /$ decade of activity for iron(III) cation. The detection limit of each sensor was established at the point of intersection of the extrapolated linear mid-range and final low concentration level segments of the calibration plot.

\subsection{Analytical Applications}

\subsubsection{Determination of Iron in Synthetic Leach Liquors from Spent Lithium Ion Batteries}

Synthetic leach liquors from spent lithium ion batteries, similar to the real ones [20], containing $1.36 \times 10^{-2} \mathrm{M} \mathrm{Mn}^{2+}, 8,48 \times 10^{-2} \mathrm{M} \mathrm{Ni}^{2+}, 1 \mathrm{M} \mathrm{Li}^{+}, 3.56 \times 10^{-2} \mathrm{M} \mathrm{Fe}^{3+}, 0,17 \mathrm{M} \mathrm{Co}^{2+}$ and $4,7 \times 10^{-2} \mathrm{M}$ $\mathrm{Cu}^{2+}$ were prepared by weighing the appropriate amount of each salt in double distillated water. The best obtained iron(III)-sensor was used for monitoring the iron in solutions by direct potentiometry. We have made three tests. First, solution A containing just the above mentioned quantities of the cations $\mathrm{Mn}^{2+}, \mathrm{Ni}^{2+}, \mathrm{Li}^{+}$and $\mathrm{Fe}^{3+}$. Solution $\mathbf{B}$ was prepared from solution $\mathrm{A}$ by adding $\mathrm{Co}^{2+}$ and solution $\mathrm{C}$ from $\mathrm{B}$ plus $\mathrm{Cu}^{2+}$. The potential of the solutions was measured to see the iron recovery. 


\subsubsection{Determination of Iron in Tap Water}

The sensor was also used for the detection of iron in three samples of tap water by direct potentiometry using a calibration graph.

\section{Results and Discussion}

\subsection{Response Characteristics of the Electrodes}

Many porphyrins $[12,21,22]$ and metalloporphyrins were used in the last years as ionophores for the developing of new polymeric membrane ion-selective electrodes. As a continuation of our previous studies regarding porphyrin based potentiometric sensors [23-26], three porphyrins (P1, P2 and P3) were used as ionophores in the preparation of polymeric membrane sensors.

First, all the membranes were obtained with the same composition, using NPOE as plasticizer and NaTPB as anion excluder. The membranes were tested as iron sensors and against a number of monovalent and bivalent cations. All the porphyrins show selectivity for iron(III). As it results from Table 1, for porphyrins P2 and P3 the results were weak from the working concentration range point of view, and also with super Nernstian values of the slopes. Porphyrin P1 plasticized with NPOE has a better working concentration range, but also a super Nernstian slope value.

It is known that the plasticizers have a strong influence on the potentiometric response of the sensors, and also on the value of the slope. Hoping for an improvement of the slope value, we have made sensors 4 and 5 by changing the plasticizer NPOE with big dielectric constant $(\varepsilon \approx 24)$ for plasticizers having lower dielectric constants: DOS $(\varepsilon \approx 4)$ and DOP $(\varepsilon \approx 5.1)$.

Table 1. Composition and response characteristics of the obtained membranes.

\begin{tabular}{|c|c|c|c|c|c|c|c|c|c|}
\hline \multirow{3}{*}{$\begin{array}{c}\text { Sensor } \\
\text { no. }\end{array}$} & \multicolumn{7}{|c|}{$\%$ Composition (w/w) of the membranes } & \multirow{3}{*}{$\begin{array}{l}\text { Working } \\
\text { concentration } \\
\text { range }(\mathbf{M})\end{array}$} & \multirow{3}{*}{ Slope $(\mathrm{mV} /$ decade) $* *$} \\
\hline & \multicolumn{3}{|c|}{ Ionophore } & \multirow{2}{*}{ PVC } & \multirow{2}{*}{ NPOE } & \multirow{2}{*}{ DOS } & \multirow{2}{*}{ DOP } & & \\
\hline & P1 & $\mathbf{P 2}$ & P3 & & & & & & \\
\hline 1 & 1 & & & 33 & 66 & & & $1 \times 10^{-7}-1 \times 10^{-2}$ & $31.2 \pm 1.0$ \\
\hline 2 & & 1 & & 33 & 66 & & & $1 \times 10^{-6}-1 \times 10^{-4}$ & $43.7 \pm 1.5$ \\
\hline 3 & & & 1 & 33 & 66 & & & $5 \times 10^{-7}-1 \times 10^{-4}$ & $41.6 \pm 1.3$ \\
\hline 4 & 1 & & & 33 & & 66 & & $1 \times 10^{-1}-1 \times 10^{-7}$ & $21.6 \pm 0.7$ \\
\hline 5 & 1 & & & 33 & & & 66 & $1 \times 10^{-6}-5 \times 10^{-2}$ & $28.8 \pm 0.8$ \\
\hline
\end{tabular}

* All the membranes contain 20 mol. \% NaTPB (relative to the ionophore); ** Standard deviation [27].

The potentiometric response toward iron(III) of the obtained sensors is presented in Figure 2. As it could be seen, both from Figure 2 and Table 1, the best results were obtained for the sensor plasticized with DOS, which has a working concentration range from $1 \times 10^{-1}-1 \times 10^{-7} \mathrm{M}$ with a near Nernstian slope of $21.6 \mathrm{mV} /$ decade of activity $\left(\mathrm{y}=-21.575 \mathrm{x}+662.16, \mathrm{R}^{2}=0.9966\right)$. For this sensor, the potentiometric answer toward the tested cations is presented in Figure 3.

The stability and reproducibility of the best obtained sensor were also tested. The standard deviation of 15 replicate measurements made for the $1 \times 10^{-3} \mathrm{M}$ solution was $\pm 0.5 \mathrm{mV}$. The sensor was used for a period of six weeks without significant changes of the potentials. 
Figure 2. Potentiometric response toward iron(III) of the obtained sensors.

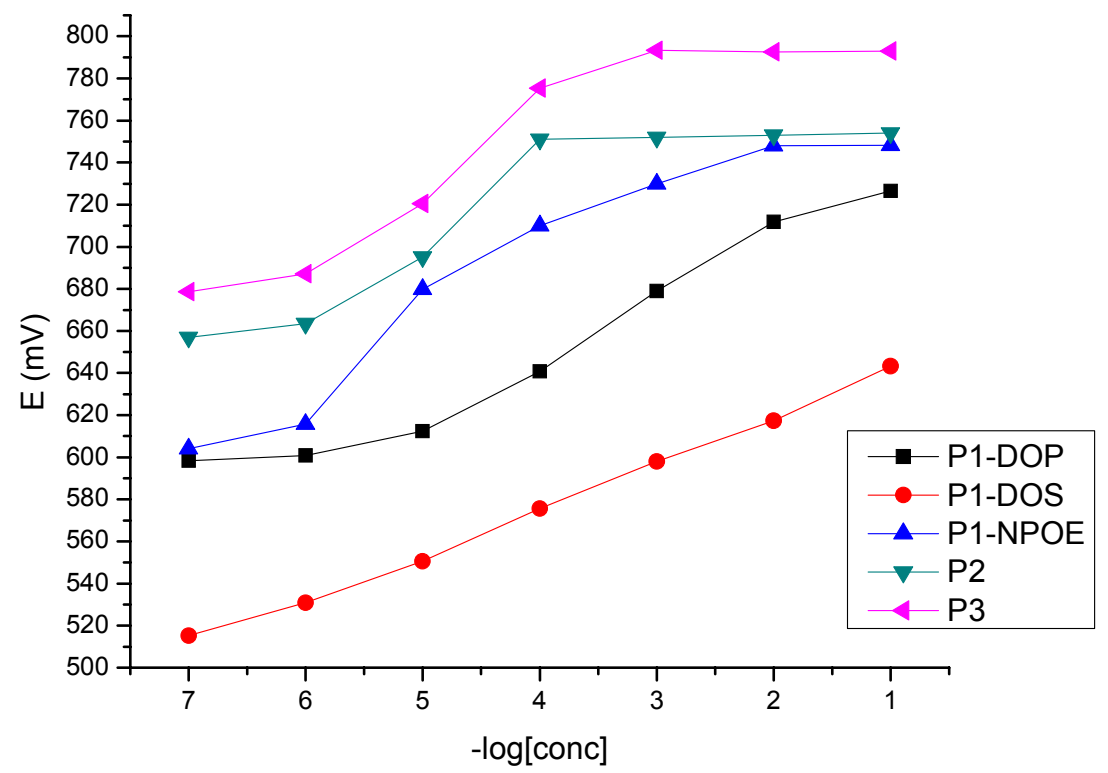

Figure 3. Potentiometric response of porphyrin P1-based sensors having the optimum composition of the membrane toward different metal ions.

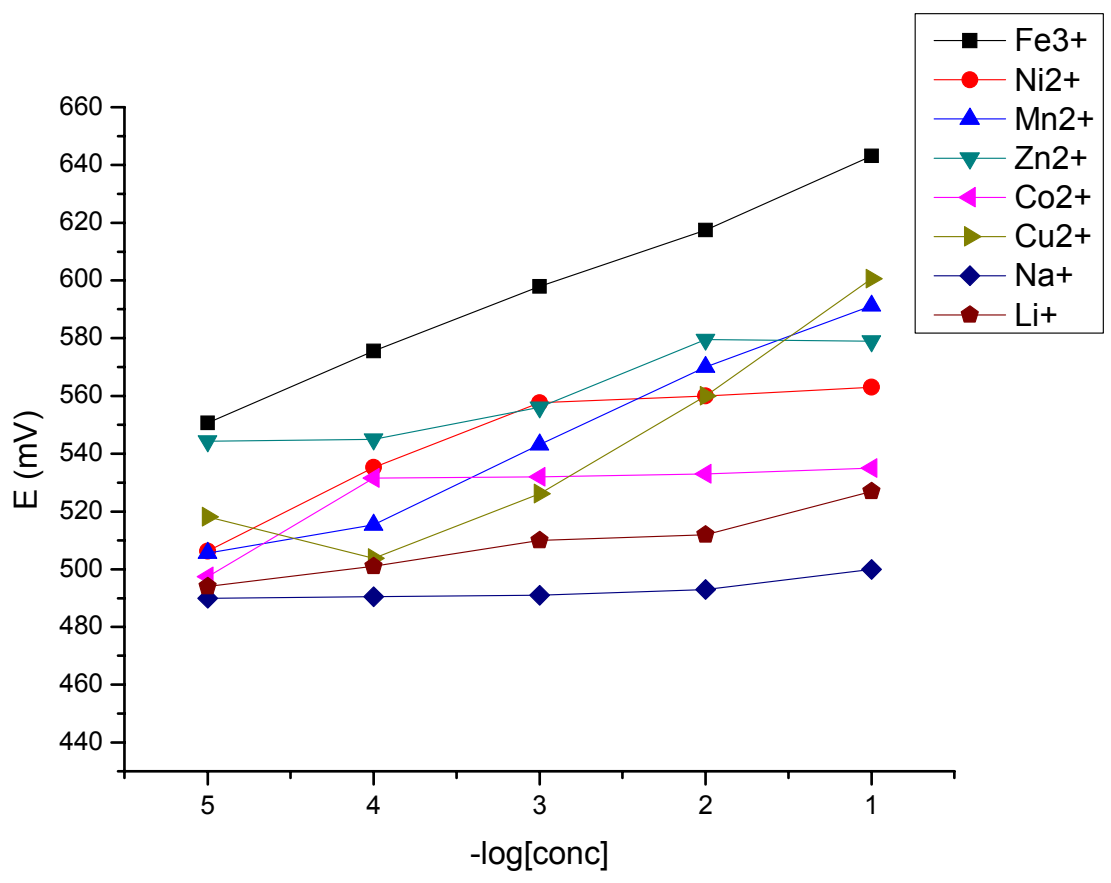

\subsection{Detection Limit and Response Time}

The practical response time of the sensor to reach $95 \%$ of the equilibrium potential was obtained after successive immersion of the electrode in a series of iron(III) ion solutions, each having a 10-fold difference in concentration. The obtained response time was about $20 \mathrm{~s}$ as the concentration of iron(III) varies from $10^{-4}$ to $10^{-3} \mathrm{M}$. The detection limit for the best performing electrode was established at the point of intersection of the extrapolated linear mid-range and final low concentration level segments of the calibration plot and it is $(8.6 \pm 0.4) \times 10^{-8} \mathrm{M}$. 


\subsection{Potentiometric Selectivity}

The potentiometric selectivity coefficients $\left(\log \mathrm{K}_{\mathrm{Fe}^{3+}, X^{+/ 2+}}^{\mathrm{pot}}\right.$ ) were calculated by the separate solution method [28] for primary and interfering cations concentration of $1 \times 10^{-2} \mathrm{M}$ and are presented in Table 2.

Table 2. Selectivity coefficients of the optimal composition membrane sensor.

\begin{tabular}{cc}
\hline Interfering cation $\mathbf{X}^{+/ 2+}$ & $\log \mathbf{K}_{\mathrm{Fe}^{3+}, X^{+/ 2+}}^{\text {pot. }}$ \\
\hline $\mathrm{Fe}^{3+}$ & 0,00 \\
$\mathrm{Ni}^{2+}$ & $-3,90$ \\
$\mathrm{Mn}^{2+}$ & $-1,40$ \\
$\mathrm{Zn}^{2+}$ & $-3,45$ \\
$\mathrm{Co}^{2+}$ & $-4,00$ \\
$\mathrm{Cu}^{2+}$ & $-2,01$ \\
$\mathrm{Na}^{+}$ & $-2,50$ \\
$\mathrm{Li}^{+}$ & $-4,28$ \\
\hline
\end{tabular}

As it could be seen from Table 2, the sensor has very good values of the selectivity coefficients, especially toward $\mathrm{Co}^{2+}, \mathrm{Ni}^{2+}$ and $\mathrm{Li}^{+}$, the main components of the leach liquor from spent lithium ion batteries.

\subsection{Effect of $p H$}

The influence of the $\mathrm{pH}$ of the test solutions on the potential response of the electrodes was studied by using the $10^{-2}$ and $10^{-3} \mathrm{M}$ iron(III) solutions adjusted with $\mathrm{HCl}$ and $\mathrm{NaOH}$ and the results are given in Figure 4.

Figure 4. Effect of the $\mathrm{pH}$ of the test solution on the potential response of the sensor with best potentiometric answer.

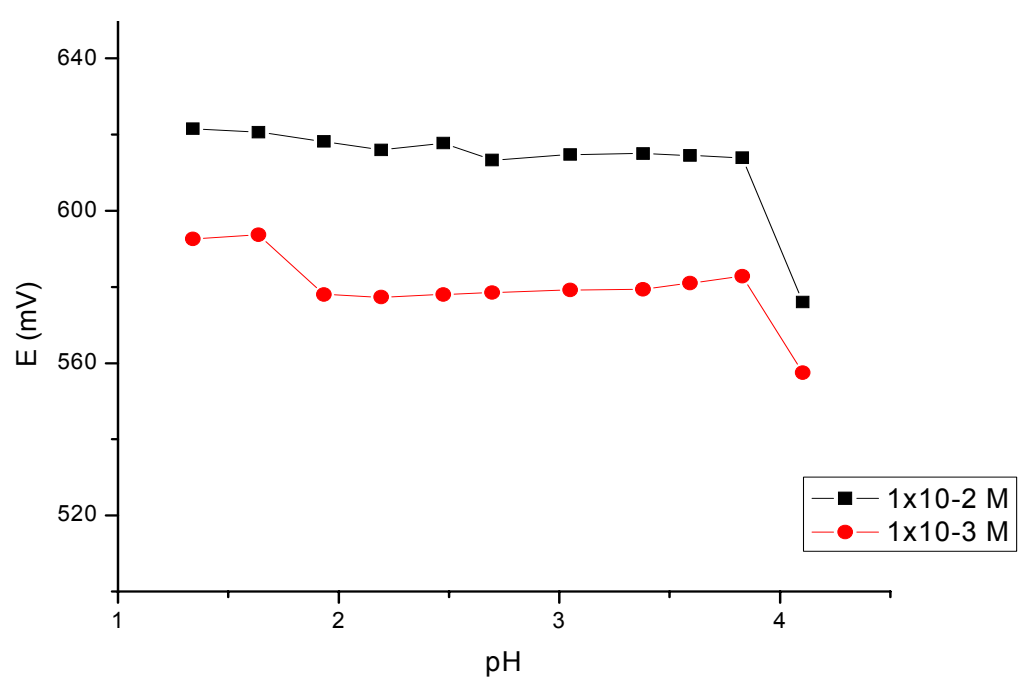

As it can be seen, the sensor may be used in a $\mathrm{pH}$ range from 2.0-3.8. Above this value of the $\mathrm{pH}$ the precipitation of iron(III) hydroxide occurs. 


\subsection{Analytical Applications of the Sensor}

As it was mentioned before, the sensor was used for monitoring of iron(III) cation in synthetic solutions from spent lithium ion batteries. The results are presented in Table 3, each of them obtained from four measurements (the standard deviation is given).

Table 3. Analytical application of the iron(III)-sensor in synthetic leach liquor.

\begin{tabular}{cccc}
\hline Sample & $\begin{array}{c}\text { Iron in solution by } \\
\mathbf{A A S}(\mathbf{g} / \mathbf{L})\end{array}$ & $\begin{array}{c}\text { Iron found by the } \\
\text { electrode }(\mathbf{g} / \mathbf{L})\end{array}$ & Recovery $\mathbf{( \% )}$ \\
\hline $\mathbf{A}$ & & $1.97 \pm 0.02$ & 99.0 \\
$\mathbf{B}$ & $1.99 \pm 0.01$ & $1.95 \pm 0.04$ & 98.0 \\
$\mathbf{C}$ & & $1.93 \pm 0.03$ & 97.0 \\
\hline
\end{tabular}

We have also tested the sensor for the determination of iron in three samples of tap water. The results, obtained for five measurements are comparatively presented with those of AAS in Table 4.

Table 4. Analytical application of the iron(III)-sensor in tap water.

\begin{tabular}{cccc}
\hline Sample & $\begin{array}{c}\text { Iron in water by } \\
\text { AAS (ppm) }\end{array}$ & $\begin{array}{c}\text { Iron found by the } \\
\text { electrode }(\mathbf{p p m})\end{array}$ & Recovery (\%) \\
\hline $\mathbf{A}$ & $5.30 \pm 0.02$ & $5.15 \pm 0.10$ & 97.2 \\
B & $2.85 \pm 0.01$ & $2.90 \pm 0.08$ & 101.7 \\
$\mathbf{C}$ & $7.53 \pm 0.05$ & $7.35 \pm 0.12$ & 97.6 \\
\hline
\end{tabular}

A good recovery of the amount of iron (III) in the samples was obtained by using the novel sensor, both at lower and higher concentrations, as it results from Tables 3 and 4.

\section{Conclusions}

A novel iron(III)-potentiometric sensor based on a novel structure, namely 5-(4-carboxyphenyl)10,15,20-tris(4-phenoxyphenyl)-porphyrin, plasticized with bis(2-ethylhexyl)sebacate, in a linear range from $1 \times 10^{-7}-1 \times 10^{-1} \mathrm{M}$ with a slope of $21.6 \mathrm{mV} /$ decade was developed. The electrode has a response time of $20 \mathrm{~s}$; works in a $\mathrm{pH}$ range from 2.0-3.8 and has a good selectivity towards a lot of cations. The sensor was used for a period of six weeks and the utility has been tested for the quantitative determination of $\mathrm{Fe}(\mathrm{III})$ in recovered solutions from spent lithium ion batteries.

\section{Acknowledgments}

The research leading to these results has received funding from the European Community's Seventh Framework Programme (FP7/2007-2013) under grant agreement $\mathrm{n}^{\circ} 266090$ (SOMABAT), Romanian PNCDI2 Program-Module III-EU $128 / 2011$ and is a result of collaboration between the coauthors within the project POSDRU/21/1.5/G/38347. 


\section{References}

1. Galhardo, C.X.; Masini, J.C. Sequential injection analysis as a tool for in situ monitoring of $\mathrm{Fe}(\mathrm{II}), \mathrm{Fe}(\mathrm{III}), \mathrm{NO}_{3}{ }^{-}$and $\mathrm{NO}_{2}{ }^{-}$in natural and waste waters. Anal. Chim. Acta 2001, 438, 39-48.

2. Kompany-Zareh, M.; Mansourian, M.; Ravaee, F. Simple method for colorimetric spot-test quantitative analysis of Fe(III) using a computer controlled hand-scanner. Anal. Chim. Acta 2002, 471, 97-104.

3. Hosseini, M.S.; Raissi, H.; Madarshahian, S. Synthesis and application of a new chelating resin functionalized with 2,3-dihydroxy benzoic acid for Fe(III) determination in water samples by flame atomic absorption spectrometry. React. Funct. Polym. 2006, 66, 1539-1545.

4. Cui, Y.; Chang, X.; Zhu, X.; Jiang, N.; Hu, Z.; Lian, N. Nanometer SiO2 modified with 5-sulfosalicylic acid as selective solid-phase extractant for Fe(III) determination by ICP-AES from biological and natural water samples. Microchem. J. 2007, 86, 23-28.

5. Mashhadizadeh, M.H.; Shoaei, I.S.; Monadi, N. A novel ion-selective membrane potentiometric sensor for direct determination of Fe(III) in the presence of Fe(II). Talanta 2004, 64, 1048-1052.

6. Mollagh, M.G.; Taher, M.A.; Ahmadi, A. PVC membrane and coated graphite potentiometric sensors based on 1-phenyl-3-pyridin-2-yl-thiourea for selective determination of iron(III). Electrochim. Acta 2010, 55, 6724-6730.

7. Gupta, V.K.; Jain, A.K.; Agarwal, S.; Maheshwari, G. An iron(III) ion-selectivesensor based on a $\mu$-bis(tridentate) ligand. Talanta 2007, 71, 1964-1968.

8. Babakhaniana, A.; Gholivanda, M.B.; Mohammadib, M.; Khodadadianc, M.; Shockravib, A.; Abbaszadehb, M.; Ghanbarya, A. Fabrication of a novel iron(III)-PVC membrane sensor based on a new 1,1'-(iminobis(methan-1-yl-1-ylidene))dinaphthalen-2-ol synthetic ionophore for direct and indirect determination of free iron species in some biological and non-biological samples. J. Haz. Mat. 2010, 177, 159-166.

9. Gupta, V.K.; Sethi, B.; Upadhyay, N.; Kumar, S.; Singh, R.; Singh, L.P. Iron (III) selective electrode based on $S$-methyl $N$-(methylcarbamoyloxy) thioacetimidate as a sensing material. Int. J. Electrochem. Sci. 2011, 6, 650-663.

10. Khun, K.; Ibupoto, Z.H.; Ali, S.M.U.; Chey, C.O.; Nur, O.; Willander, M. Iron ion sensor based on functionalized $\mathrm{ZnO}$ nanorods. Electroanalysis 2012, 24, 521-528.

11. Zamania, H.A.; Ganjali, M.R.; Behmadi, H.; Behnajady, M.A. Fabrication of an iron(III) PVC-membrane sensor based on bis-benzilthiocarbohydrazide as a selective sensing material. Mater. Sci. Eng. 2009, 29, 1535-1539.

12. Fakhari, A.R.; Alaghemand, M.; Shamsipur, M. Iron(III)-selective membrane potentiometric sensor based on 5,10,15,20-tetrakis(pentafluorophenyl)-21H,23H-porphyrin. Anal. Lett. 2001, 34, 1097-1106.

13. Lee, C.K.; Rhee, K.-I. Reductive leaching of cathodic active materials from lithium ion battery wastes. Hydrometallurgy 2003, 68, 5-10.

14. Ismael, M.R.C.; Carvalho, J.M.R. Iron recovery from sulphate leach liquors in zinc hydrometallurgy. Miner. Eng. 2003, 16, 31-39. 
15. Fagadar-Cosma, E.; Fagadar-Cosma, G.; Vasile, M.; Enache, C. Synthesis, spectroscopic and self-assembling characterization of novel photoactive mixed aryl-substituted porphyrin. Curr. Org. Chem. 2012, 16, 931-941.

16. Bakar, M.B.; Oelgemoller, M.; Senge, M.O. Lead structures for applications in photodynamic therapy. Part 2: Synthetic studies for photo-triggered release systems of bioconjugate porphyrin photosensitizers. Tetrahedron 2009, 65, 7064-7078.

17. Adler, A.D.; Longo, F.R.; Kampas, F.; Kim, J. Preparation of metalloporphyrins. J. Inorg. Nucl. Chem. 1970, 32, 2443-2445.

18. Fagadar-Cosma, E.; Cseh, L.; Badea, V.; Fagadar-Cosma, G.; Vlascici, D. Combinatorial synthesis and characterization of new asymmetric porphyrins as potential photosensitizers in photodynamic therapy. Comb. Chem. High Throughput Screen. 2007, 10, 466-472.

19. Balaz, M.; Holmes, A.E.; Benedetti, M.; Proni, G.; Berova, N. Porphyrin substituted phosphoramidites: New building blocks for porphyrin-oligonucleotide syntheses. Bioorgan. Med. Chem. 2005, 13, 2413-2421.

20. Granata, G.; Moscardini, E.; Pagnanelli, F.; Trabucco, F.; Toro, L. Product recovery from Li-ion battery wastes coming from an industrial pretratment plant: Lab scale tests and process simulations. J. Power Sources 2012, 206, 393-401.

21. Gupta, V.K.; Jain, A.K.; Maheshwari, G.; Lang, H.; Ishtaiwi, Z. Copper(II)-selective potentiometric sensors based on porphyrins in PVC matrix. Sens. Actuators B 2006, 117, 99-106.

22. Gupta, V.K.; Chauhan, D.K.; Saini, V.K.; Agarwal, S.; Antonijevic, M.M.; Lang, H. A porphyrin based potentiometric sensor for $\mathrm{Zn}^{2+}$ determination. Sensors 2003, 3, 223-235.

23. Vlascici, D.; Făgădar-Cosma, E.; Bizerea Spiridon, O. A new composition for Co(II)-porphyrinbased membranes used in thiocyanate-selective electrodes. Sensors 2006, 6, 892-900.

24. Vlascici, D.; Bizerea Spiridon, O.; Făgădar-Cosma, E. Thiocyanate-selective electrode based on rhodium porphyrin derivatives. J. Optoelectron. Adv. Mater. 2006, 8, 883-887.

25. Vlascici, D.; Fagadar Cosma, E.; Pica, E.M.; Cosma, V.; Bizerea, O.; Mihailescu, G.; Olenic, L. Free base porphyrins as ionophores for heavy metal sensors. Sensors 2008, 8, 4995-5004.

26. Vlascici, D.; Pruneanu, S.; Olenic, L.; Pogacean, F.; Ostafe, V.; Chiriac, V.; Pica, E.M.; Bolundut, L.C.; Nica, L.; Fagadar Cosma, E. Manganese(III) porphyrins based potentiometric sensors for diclofenac assay in pharmaceutical preparations. Sensors 2010, 10, 8850-8864.

27. de Bievre, P.; Dybkaer, R.; Fajgelj, A.; Hibbert, D.B. Metrological traceability of measurements results in chemistry: Concepts and implementation (IUPAC Technical report). Pure Appl. Chem. 2011, 83, 1873-1935.

28. Umezawa, Y.; Buhlmann, P.; Umezawa, K.; Tohda, K. Potentiometric selectivity coefficients of ion-selective electrodes. Part I Inorganic cations. Pure Appl. Chem. 2000, 72, 1851-2082.

(C) 2012 by the authors; licensee MDPI, Basel, Switzerland. This article is an open access article distributed under the terms and conditions of the Creative Commons Attribution license (http://creativecommons.org/licenses/by/3.0/). 